\title{
Mucinous Cystadenoma of the Ovary Associated with Hyperplasia of Stromal Leydig Cells in Pregnant Woman
}

\author{
Vladimír Bartoš
}

\begin{abstract}
Background: The hormonally induced non-neoplastic lesions of ovarian stroma during pregnancy must be recognized by pathologist in order to avoid mistaking them for true tumors.

Case report: A 28-year-old woman was delivered of a healthy infant by cesarean section. As an incidental finding, a multicystic tumor in the left ovary was found and resected. Histopathology was consistent with benign mucinous cystadenoma. In addition, within the stroma beneath the lining mucinous epithelium, a dense population of cohesive polygonal cells with abundant eosinophilic cytoplasm, typically resembling the Leydig cells, was seen. They were uniform without atypia, accompaning by minimal proliferative activity. They strongly expressed vimentin, inhibin, CD99 and calretinin. The final diagnosis of mucinous cystadenoma associated with hyperplasia of stromal Leydig cells was made.

Conclusions: Leydig cell hyperplasia belongs to the specific changes of ovarian stroma associated with pregnancy. The present case stresses that in such situation the pathologists should be aware of it and not confuse it with a tumor.
\end{abstract}

\section{Keywords}

Mucinous Cystadenoma; Leydig Cell Hyperplasia; Ovary; Pregnancy; Immunohistochemistry

Martin's Biopsy Center, Ltd., Martin, Slovakia

E-mail: vladim.bartos@gmail.com

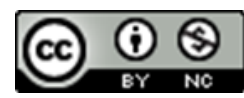

Copyright @Vladimír Bartoš, 2021

\section{Background}

Primary ovarian tumors are a frequent and histogenetically very diverse group of neoplasms that may affect females at any age [1-3]. They commonly occur during reproductive life, but they are rarely first diagnosed during pregnancy [1-3]. The reported incidence of ovarian neoplasms that were found in pregnant women varies highly according to various studies. Based on the published reports, the incidence has ranged from 1:76 to 1:2328 [1]. It is not only dependent on the population being studied but is also greatly influenced by the frequency of routine prenatal ultrasound examinations in that population [1]. About $95 \%$ of ovarian tumors in the pregnancy are benign lesions [1]. Since a pregnancy is accompanied by significant hormonal changes, they often result in specific structural modifications of ovarian stroma. Such changes may lead to pitfalls in a biopsy evaluation of ovarian tissue, that could be simultaneously affected by tumor. In the present article, an unusual case of mucinous cystadenoma of the ovary associated with hyperplasia of stromal Leydig cells in a young pregnant women is described.

\section{Clinical History}

A 28-year-old woman with no significant previous medical history was delivered of a healthy infant by cesarean section at 37 weeks of pregnancy. As an incidental finding, a multicystic tumor in the left ovary was found during the surgical procedure. It measured about $10 \mathrm{~cm}$ in diameter and appeared to be well circumscribed with a smooth external surface. After finishing the cesarean birth, a resection of tumor was performed while the rest of intact ovarian tissue was left situ. The contralateral ovary did not show any pathological findings. No complications were encountered during the surgery and postoperative recovery was uneventful. 


\section{Materials and Methods}

The obtained specimen was processed into ten formalin-fixed paraffin-embedded tissue blocks which were then stained with hematoxylin-eosin (H\&E) and investigated in a conventional light microscope (Nicon Eclipse Ci). Selected sections were stained with alcian blue and analyzed immunohistochemically with monoclonal mouse anti-human antibodies against the following antigens: CK7 (clone OV-TL 12/30, DAKO, ready-to-use), vimentin (clone V9, DAKO, ready-to-use), inhibin $\alpha$ (clone R1, DAKO, dilution 1:25), CD99 (clone 12E7, DAKO, ready-to-use) calretinin (clone DAK-Calret 1, DAKO, ready-to-use) chromogranin A (clone LK2H10, ROCHE, ready-to-use), synaptophysin (clone DAK-SYNAP, DAKO, ready-to-use), CD56 (clone 123C3, DAKO, readyto-use), estrogen receptor (clone 1D5, DAKO, ready-to-use) and Ki-67 (clone MIB1, DAKO, ready-to-use). Proliferation $\mathrm{Ki}-67$ index was calculated as a percentage of positive cells in hot spot regions (per 10 high-power-fileds) with highest nuclear staining.

\section{Results}

Grossly, the resected tumor mass measured $10 \times 7 \times 3 \mathrm{~cm}$ and consisted of multiple cysts of various size. They were filled with mucinous fluid. The maximum thickness of the cyst wall was $1 \mathrm{~cm}$. On cut sections, no papillary structures were identified. Microscopically, the cysts were lined by a single layer of non-ciliated columnar cells with basally located nuclei and intracellular mucin. They did not show atypia and exhibited a very low proliferation index $(\mathrm{Ki}-67<5 \%)$. Histopathology was consistent with benign mucinous cystadenoma. In addition, within the stroma beneath the lining mucinous epithelium, a dense population of cohesive polygonal cells with abundant eosinophilic cytoplasm, a central round nucleus, and a prominent nucleolus, typically resembling the Leydig cells, was seen (Figure 1 and 2). They were uniform without atypia, accompaning by minimal proliferation activity (Ki-67 index $<1 \%$ ). Some of them contained inconspicious brown pigment in the cytoplasm. No crystalls of Reinke were identified. By immunohistochemistry, columnar epithelium of cystadenoma expressed CK7 (Figure 3). Leydig cells were strongly positive for vimentin, inhibin $\alpha$ (Figure 4), CD99 (Figure 5) and calretinin, sporadically positive for CD56 and negative for chromogranin A, synaptophysin, CK7 and estrogen receptor. In addition, the foci of ectopic decidua in the stroma were visible. The final diagnosis of benign mucinous cystadenoma associated with hyperplasia of Leydig cells and deciduosis was made based on the pathological and immunohistochemical findings.

As for further clinical course, the tumor recurred 4 months after surgery. The ovary was then completely resected and histology revealed an identical mucinous cystadenoma, but without those stromal changes.

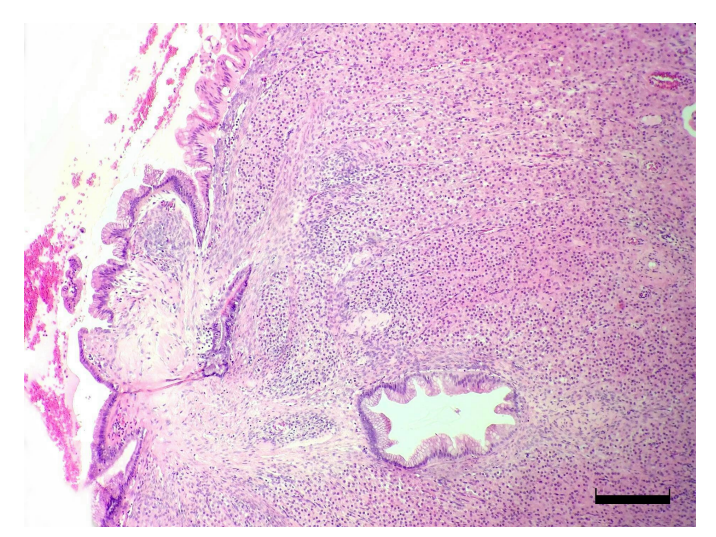

Figure 1. The wall of the mucinous cystadenoma with hyperplastic Leydig cells subtending the epithelium. A single mucinous gland is entrapped within dense Leydig cell population. (H\&E, original magnification $40 \times$, scale bar $125 \mu \mathrm{m})$

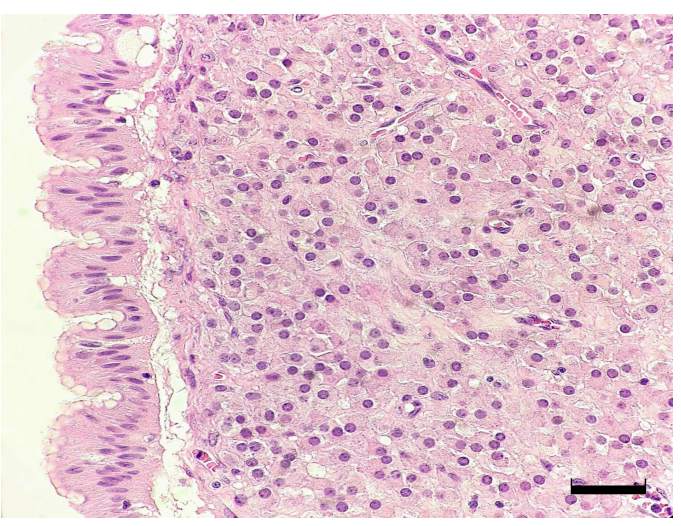

Figure 2. A more detailed view on the columnar epithelium of the mucinous cystadenoma (left) and Leydig cell population (right). (H\&E, original magnification $100 \times$, scale bar $50 \mu \mathrm{m}$ )

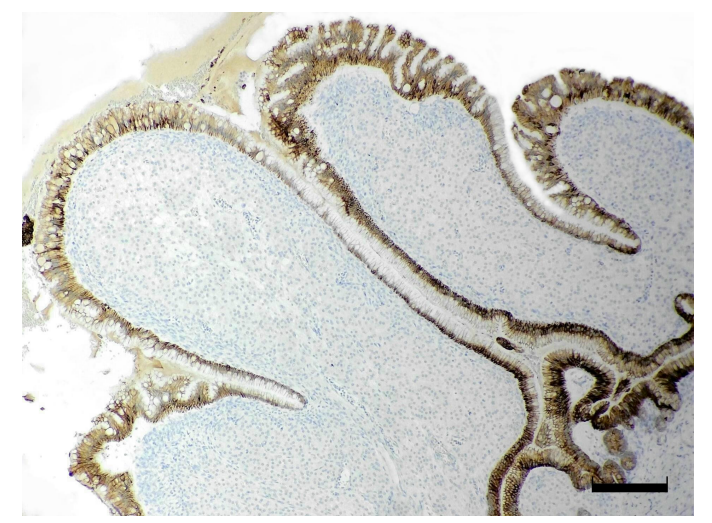

Figure 3. Strong immunohistochemical expression of CK7 in the columnar epithelium of the mucinous cystadenoma. (original magnification $60 \times$, scale bar $85 \mu \mathrm{m}$ ) 


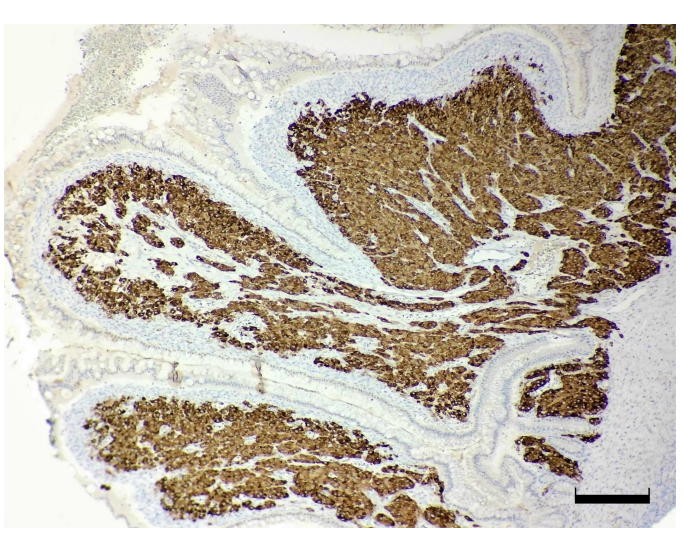

Figure 4. Strong immunohistochemical expression of inhibin $\alpha$ in hyperplastic Leydig cell population. (original magnification $60 \times$, scale bar $85 \mu \mathrm{m}$ )

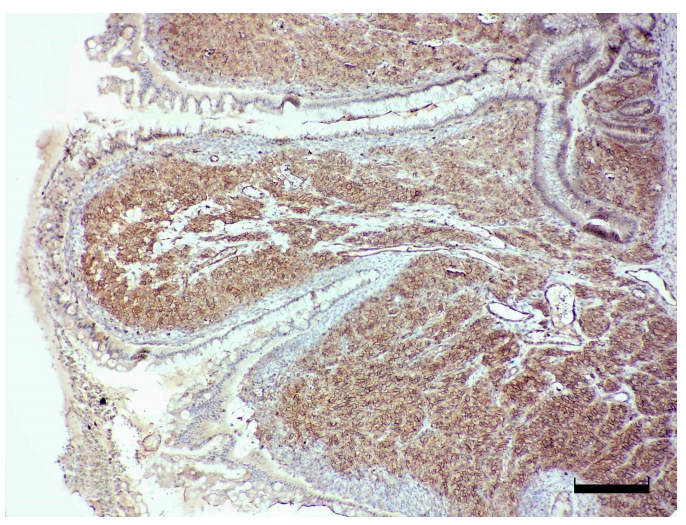

Figure 5. Strong immunohistochemical expression of CD99 in hyperplastic Leydig cell population. (original magnification $60 \times$, scale bar $85 \mu \mathrm{m}$ )

\section{Discussion}

Mucinous cystadenoma comprises $13 \%$ of all benign ovarian epithelial neoplasms [2]. It manifests as unilocular or multilocular tumor of variable size, ranging from a few centimeters to over $30 \mathrm{~cm}[2,4,5]$. It is typically unilateral (95\%) [2]. The vast majority are composed of cysts and glands lined by simple non-stratified mucinous epithelium resembling gastric foveolar-type epithelium or intestinal epithelium containing goblet cells $[2,4,5]$. Due to the characteristic histopathologic features, a biopsy diagnosis is usually not problematic. In the present case, the principal diagnostic pitfall was a population of hyperplastic Leydig cells in the wall of the cystadenoma, at first glance reminiscent of luteinized variant of granulosa cell tumor or Leydig cell tumor [6,7].

The cells in the ovarian stroma are highly responsive to circulating gonadotropins and steroid hormones, and as it has been already mentioned, this may lead to specific ovarian changes during pregnancy. The spectrum of tumor-like lesions of the ovary associated with an otherwise normal pregnancy is as follows: nodular theca-lutein hyperplasia (pregnancy luteoma), hyperreactio luteinalis, deciduosis, granulosa cell proliferations, and Leydig cell hyperplasia $[2,3]$. These hormonally induced non-neoplastic lesions must be recognized by pathologist in order to avoid mistaking them for true tumors. They involute spontaneously after the pregnancy ends and radical surgery is clearly inappropriate treatment [3].

Leydig cell hyperplasia has a close association with pregnancy [3]. It is usually asymptomatic but may be found incidentally in ovaries biopsied or excised for indications such as tumor [3]. Leydig cell hyperplasia is generally of a mild degree and unassociated with clinical endocrine disturbance, although there may be sometimes increased serum testosterone [3]. Microscopically, it appears as clusters and nodules of typical rounded and polygonal Leydig cells with moderately sized, vesicular, central nuclei and eosinophilic cytoplasm [3]. The nodules or clusters of Leydig cells vary greatly from area to area, but are most prominent in ovarian hilus. Yellow-brown intracytoplasmic lipochrome (lipofuscin) pigment is often focally observed, and Reinke crystalloids are sometimes found in occasional cells although they may be sparse [3]. Their prominence does not correlate with the severity of the hyperplasia. Nuclear pleomorphisms is not common [3].

In routine biopsy practice, mucinous cystadenoma of the ovary coexisting with Leydig cell hyperplasia and/or hyperplasia of luteinized cells in the ovarian stroma during pregnancy is a quite rare finding. Only a few such cases have been published untill now [8-10]. Probably the first case was described by Pascal \& Grecco [8] in 1988. They reported a 32-year-old woman, who was found to have a large ovarian cyst during cesarean section. The cyst proved to be a mucinous cystadenoma with prominent luteinization of the stroma and with numerous foci of hyperplastic Leydig cells in the cyst wall. Qublan et al. [9] described a 32-yearold woman with a cystic tumor in the right ovary, that was diagnosed 1 month before conception. Cesarean delivery of a normal infant took place, and the removal of a huge ovarian cystic mass was also performed. Histopathology confirmed a mucinous cystadenoma with a marked stromal luteinization. Antoniou et al. [10] reported a 30-year-old woman who was diagnosed as having a large tumor of the right ovary during cesarean section. The tumor was a mucinous cystadenoma with cellular masses typically resembling lutein stromal cells or Leydig cells in the cyst wall. In some cases, this phenomenon may be associated with an overproduction of testosterone. Kucur et al. [11] reported a 22-year-old woman with a huge mucinous cystadenoma of the ovary with marked luteinizing stroma complicating pregnancy and causing virilization and premature labor. Even Bolat et al. [12] presented a case of an ovarian mucinous cystadenoma with a stromal luteinization during pregnancy, that was the cause of virilization and fetal intrauterine growth restriction. In our patient, no obvious signs of virilization were clinically noted. 


\section{Conclusions}

The vast majority of tumors and non-tumorous lesions of the ovaries are histologically diagnosed outside of pregnancy. As a result, the pregnancy-related specific changes of ovarian stroma, such as Leydig cell hyperplasia, are very rarely encountered in the biopsy examination. The present case stresses that in such situation the pathologists should be aware of it and not confuse it with a tumor.

\section{Ethical Statement}

The study was conducted according to WHO Declaration of Helsinki - Ethical Principles for Medical Research Involving Human Subjects.

\section{Informed Consent}

Informed consent was obtained from the patient.

\section{Conflict of Interest}

The author declares that no conflicts exist.

\section{Financial Disclosure}

The author declared no financial support.

\section{Acknowledgement}

The author greatly thank MUDr. Pavol Slávik (pathologist) for educational support and MUDr. Roman Chovanec (gynecologist) for providing the clinical information.

\section{References}

[1] Aggarwal P, Kehoe S. Ovarian tumours in pregnancy: a literature review. European Journal of Obstetrics \& Gynecology and Reproductive Biology [Internet]. 2011 Apr;155(2):119-124. Available from: https://doi.org/10.1016/j.ejogrb.2010.11.023

[2] Kurman RJ, Hedrick Ellenson L, Ronnett BM, editors. Blaustein's pathology of the female genital tract. Cham: Springer International Publishing; 2019. Available from: https://doi.org/10.1007/978-3-319-46334-6

[3] Robboy S, Mutter G, Prat J, Bentley R, Russell P, Anderson M. Pathology of the female reproductive tract, 2nd edition. Churchill Livingstone: Elsevier; 2008.

[4] Silva E, Malpica A, Roma A, Ramalingam P, Kim G, Bakkar R, et al. Ovarian mucinous neoplasms, intestinal type, in premenopausal patients, develop in abnormal ovaries. Human Pathology [Internet]. 2021 Feb;108:32-41. Available from: https://doi.org/10.1016/j.humpath.2020.11.003

[5] Watkins JC, Young RH. Müllerian mucinous cystadenomas of the ovary. International Journal of Gynecological Pathology [Internet]. 2021 Feb 11; Publish Ahead of Print. Available from: https://doi.org/10.1097/PGP.0000000000000765
[6] Andreetta M, Dall'Igna P, De Corti F, Gamba P, Virgone C. Metachronous Contralateral Cystadenoma After Ovariectomy for Juvenile Granulosa Cell Tumor in a Young Girl: An Uncommon Association. Journal of Pediatric and Adolescent Gynecology [Internet]. 2021 Feb;34(1):103-105. Available from: https://doi.org/10.1016/j.jpag.2020.07.016

[7] Bdioui A, Bchir A, Missaoui N, Hamchi H, Hmissa S, Mokni M. Inhabitual presentation of Sertoli-Leydig cell tumor of the ovary with xeroderma pigmentosum: Case report with review of literature. International Journal of Surgery Case Reports [Internet]. 2021 Jan;78:288-291. Available from: https://doi.org/10.1016/j.ijscr.2020.12.019

[8] Pascal RR, Grecco LA. Mucinous cystadenoma of the ovary with stromal luteinization and hilar cell hyperplasia during pregnancy. Human Pathology [Internet]. 1988 Feb;19(2):179-180. Available from: https://doi.org/10.1016/S0046-8177(88)80345-9

[9] Qublan HS, Al-Ghoweri AS, Al-Kaisi NS, Abu-khait Sami A. Benign mucinous cystadenoma with stromal luteinization during pregnancy: A hormonally responsive tumor and a rare cause of fetal intrauterine growth restriction. Journal of Obstetrics and Gynaecology Research [Internet]. 2002 Apr;28(2):104-107. Available from: https://doi.org/10.1046/j.1341-8076.2002.00020.x

[10] Antoniou N, Varras M, Akrivis C, Demou A, Bellou A, Stefanaki S. Mucinous cystadenoma of the ovary with functioning stroma and virilization in pregnancy: a case report and review of the literature. Clin Exp Obstet Gynecol [Internet]. 2003;30(4):248-252. Available from: http://www.ncbi.nlm.nih.gov/pubmed/14664425

[11] Kucur SK, Acar C, Temizkan O, Ozagari A, Gozukara I, Akyol A. A huge ovarian mucinous cystadenoma causing virilization, preterm labor, and persistent supine hypotensive syndrome during pregnancy. Autopsy and Case Reports [Internet]. 2016;6(2):39-43. Available from: https://doi.org/10.4322/acr.2016.029

[12] Bolat F, Parlakgumus A, Canpolat T, Tuncer I. Benign mucinous cystadenoma with stromal luteinization responsible for maternal virilization and fetal intrauterine growth restriction. Journal of Obstetrics and Gynaecology Research [Internet]. 2011 Mar 31;37(7):893-896. Available from: https://doi.org/10.1111/j.14470756.2010.01406.x

Received: 2021-01-21

Revised: $2021-03-18$

Accepted: 2021-03-24 